Supporting Information

\title{
Highly dense packing of chromophoric linkers achievable in a pyrene-based MOF for photoelectric response
}

Jian-Hua Qin, ${ }^{\dagger}$ Ya-Dan Huang, ${ }^{\dagger}, \dagger$ Ying Zhao, ${ }^{\dagger}$ Xiao-Gang Yang, ${ }^{*}, \dagger$ Fei-Fei Li, $, *,+$ Chao Wang,${ }^{\dagger}$ and Lu-Fang Ma*,†,

†College of Chemistry and Chemical Engineering, Henan Key Laboratory of Function-Oriented Porous Materials, Luoyang Normal University, Luoyang 471934, PR. China

†College of Chemistry and Chemical Engineering, Henan Polytechnic University, Jiaozuo, 454000, PR. China 


\section{A. Experimental Section}

\section{Materials and general procedures.}

2. Synthesis of $\left[\mathrm{Zn}(\mathrm{TBAPy})_{1 / 2}\left(\mathrm{H}_{2} \mathrm{O}\right)_{2}\right](1)$.

\section{Preparation of working electrode.}

\section{Theoretical calculations of 1 .}

\section{B. Supporting Figures}

Fig. S1 (a) PXRD patterns of 1; the simulated, as-synthesized, and after soaked in 0.5 M sodium sulfate aqueous solution for $24 \mathrm{~h}$. (b) Thermogravimetric curve of $\mathbf{1}$.

Fig. S2 View of local coordination environment of $\mathrm{Zn}(\mathrm{II})$ ion in 1 . Symmetry codes: A -1+X, 1/2-Y, $-1 / 2+Z$.

Fig. S3 View of 2D zig-zag layer constructed from TBAPy ligands along the $c$-axis direction. Coordinated water molecules and $\mathrm{H}$ atoms are omitted for clarity.

Fig. S4 Rotation of the benzoate group to minimise any steric interactions between the $\mathrm{H}$ atoms of phenyl and pyrene core.

Fig. S5 (a) The distances between the benzoate centroids of the TBAPy in 1. The separations of $\mathrm{Zn}(\mathrm{II})$ ions linked by one single TBAPy ligand. (b) The separations of two paralleled pyrene cores in one 2D layer.

Fig. S6 View of 3D supramolecular framework of 1, which shows a staggered overlap between 2D zig-zag layers.

Fig. S7 View of single (a) and slip stacking (b) 2D layer of $\left[\mathrm{Zn}_{2}(\right.$ TBAPy $\left.)\left(\mathrm{H}_{2} \mathrm{O}\right)_{2}\right] \cdot(\text { Guests) })_{x}(2)$ along [101] and [010] direction, respectively. Reproduced with permission from ref 6. Copyright 2012 American Chemical Society.

Fig. S8 View of single (a) and slip stacking (b) 2D layer of $\left[\mathrm{Zn}_{2}(\mathrm{TBAPy})\left(\mathrm{H}_{2} \mathrm{O}\right)_{2}\right] \cdot 3.5 \mathrm{DEF}$ (4). Reproduced with permission from ref 7. Copyright 2015 Royal Society of Chemistry.

Fig. S9 View of the 3D network of $\left[\mathrm{Zn}_{2}(\mathrm{TBAPy})\right](3)$ (a), in which TBAPy ligands are arranged in a parallel stacking mode with the separation between pyrene cores of $4.798 \AA$ (b). Reproduced with permission from ref 6. Copyright 2012 American Chemical Society.

Fig. S10 Normalized excitation and emission spectra of $\mathrm{H}_{4} \mathrm{TBAPy}$ in solid state at room temperature.

Fig. S11 The calculated HOMO and LUMO profiles based on PDFT calculations of 1.

Fig. S12 Calculated orbital energy level of 1. 
Fig. S13 Fluorescence spectra of 1 measured from 293 to $460 \mathrm{~K}$ (a) and 460 to $293 \mathrm{~K}$ (b). CIE-1931 chromaticity diagram showing the fluorescence emission of 1 from 293 to $460 \mathrm{~K}$ (c).

Fig. S14 Cyclic voltammogram of bare ITO and 1 modified ITO in $0.5 \mathrm{M} \mathrm{Na}_{2} \mathrm{SO}_{4}$ aqueous solution.

Fig. S15 LSV curves of bare ITO and 1 modified ITO in $0.5 \mathrm{M} \mathrm{Na}_{2} \mathrm{SO}_{4}$ aqueous solution.

Fig. S16 PXRD patterns of 1; the simulated, and after the photoelectron performance test.

\section{Supporting Tables}

Table S1. Concentration of TBAPy Linker in TBAPy-based MOFs.

Table S2. Crystallographic data and experimental details for $\mathbf{1}$.

Table S3. Selected bond distances $/ \AA$ and bond angles $/ \circ$ for $\mathbf{1}$.

\section{Supporting References}




\section{A. Experimental Section}

\section{Materials and general procedures.}

All reagents were of analytical grade and obtained from commercial sources without further purification. Elemental analysis for $\mathrm{C}$ and $\mathrm{H}$ were performed on a Perkin-Elmer 240 elemental analyzer. Powder X-ray diffraction analyses (PXRD) patterns were collected on a Bruker D8-ADVANCE X-ray diffractometer with $\mathrm{Cu} K \alpha$ radiation $(\lambda=1.5418 \AA)$. Measurements were made in a $2 \theta$ range of $5-50^{\circ}$ at room temperature with a step of $0.02^{\circ}(2 \theta)$ and a counting time of $0.2 \mathrm{~s} / \mathrm{step}$. The operating power was $40 \mathrm{KV}, 30 \mathrm{~mA}$. Thermogravimetric analysis (TGA) experiments were carried out using SII EXStar6000 TG/DTA6300 thermal analyzer from room temperature to $800{ }^{\circ} \mathrm{C}$ under a nitrogen atmosphere at a heating rate of $10^{\circ} \mathrm{C} \mathrm{min}^{-1}$.

Single-crystal X-ray diffraction data for $\mathbf{1}$ was collected at room temperature on an Oxford Diffraction SuperNova area-detector diffractometer using mirror optics monochromated Mo Ka radiation $(\lambda=0.71073 \AA)$. CrysAlisPro ${ }^{1}$ was used for the data collection, data reduction and empirical absorption correction. The crystal structure was solved by direct methods, using SHELXS-2014 and least-squares refined with SHELXL-2014² using anisotropic thermal displacement parameters for all non-hydrogen atoms. The crystallographic data for $\mathbf{1}$ are listed in Table S2 and S3. CCDC No. 1920675 contain the supplementary crystallographic data for $\mathbf{1}$. This material can be obtained free of charge via http://www.ccdc.cam.ac.uk/conts/retrieving.html, or from the Cambridge Crystallographic Data Centre, 12 Union Road, Cambridge CB2 1EZ, UK; fax: (+44) 1223-336-033; or E-mail: deposit@ccdc.cam.ac.uk.

Photographs of MOF powder under day light and UV excitation (365 nm) were captured using a Huawei P3 Mobile Phone. UV-vis absorption spectra was measured using a Shimadzu UV-3600 plus UV-vis-NIR spectrophotometer. Room temperature PL spectra and time-resolved lifetime were conducted on an Edinburgh FLS1000 fluorescence spectrometer equipped with a xenon arc lamp (Xe900), nanosecond flash-lamp (nF900) and a microsecond flashlamp with time-resolved single photon counting-multi-channel scaling (MCS) mode. The temperature dependence of the PL spectra were measured using a temperature controller attached to a cryostat (Oxford Ltd. Optistat DN2) using an FLS1000 fluorescence spectrometer.

Optoelectronic performances were tested with a CHI 660E electrochemical analyzer (CH Instruments, Chenhua Co., Shanghai, China) in a standard three-electrode system. $\mathrm{Ag} / \mathrm{AgCl}$ as a reference electrode, a platinum wire electrode as a counter electrode, powder of $\mathbf{1}$ modified indium tin oxide (ITO) as the 
working electrode (working area of $1.0 \mathrm{~cm}^{2}$ ), and $0.5 \mathrm{M}$ sodium sulfate aqueous solution as electrolyte. The system was irradiated by a $300 \mathrm{~W}$ Xe lamp $(\lambda>420 \mathrm{~nm})$. Linear-sweep voltammograms (LSV) with a scan rate of $50 \mathrm{mV} / \mathrm{s}$, transient photocurrent responses with the on-off cycle's illumination at 0 , 0.4 and $-0.4 \mathrm{~V}$ bias potential (vs. $\mathrm{Ag} / \mathrm{AgCl}$ ) were tested in three-electrode system at ambient pressure and room temperature.

The incident photon-to-current efficiency (IPCE) at each wave-length was measured under continous monochromatic light illumination in a standard three-electrode system. $\mathrm{Ag} / \mathrm{AgCl}$ as a reference electrode, a platinum wire electrode as a counter electrode, powder of $\mathbf{1}$ modified ITO as the working electrode (working area of $1.0 \mathrm{~cm}^{2}$ ), and $0.5 \mathrm{M}$ sodium sulfate aqueous solution as electrolyte. Monochromatic light was generated using the Omni- $\lambda 150$ monochromator, and the output power was measured using a photodiode detector. IPCE was calculated based on the equation: IPCE $=(1240 I) /(\lambda$ $\left.P_{\text {light }}\right)$, where $I$ is the photocurrent density $\left(\mathrm{mA} \mathrm{cm}^{-2}\right), \lambda$ is the incident light wavelength $(\mathrm{nm})$, and $P_{\text {light }}$ is the power density of monochromatic light at each wavelength $\left(\mathrm{mW} \mathrm{cm}^{-2}\right)$.

\section{Synthesis of $\left[\mathrm{Zn}(\mathrm{TBAPy})_{1 / 2}\left(\mathrm{H}_{2} \mathrm{O}\right)_{2}\right](1)$.}

The reaction of $\mathrm{H}_{4}$ TBAPy with $\mathrm{ZnSO}_{4}$ in a mixture of acetonitrile $\left(\mathrm{CH}_{3} \mathrm{CN}\right) / \mathrm{H}_{2} \mathrm{O} /[\mathrm{BMPi}] \mathrm{Br}(2 / 2 / 1)$ at $160^{\circ} \mathrm{C}$ yields yellow X-ray quality single crystals of the two-dimensional framework [Zn(TBAPy $\left.)_{1 / 2}\left(\mathrm{H}_{2} \mathrm{O}\right)_{2}\right]$ (1). In detail, a mixture of $\mathrm{ZnSO}_{4}(0.2 \mathrm{mmol})$ and $\mathrm{H}_{4}$ TBAPy $(0.05 \mathrm{mmol})$ in a 5 $\mathrm{mL}$ mixed solvent $\left(\mathrm{CH}_{3} \mathrm{CN}\right) / \mathrm{H}_{2} \mathrm{O} /[\mathrm{BMPi}] \mathrm{Br}(2 / 2 / 1)$ was placed in a $25 \mathrm{~mL}$ Teflonlined stainless steel vessel. The vessel was sealed and heated to $160{ }^{\circ} \mathrm{C}$ for $72 \mathrm{~h}$ and then cooled to room temperature at a rate of $5{ }^{\circ} \mathrm{C} \cdot \mathrm{h}^{-1}$. Yellow block crystals of 1 were obtained in high yields $(\sim 90 \%)$. Elemental analysis calcd (\%) for $1 \mathrm{C}_{22} \mathrm{H}_{15} \mathrm{O}_{6} \mathrm{Zn}$ (440.71): C 59.95, H 3.43. found: C 57.83, H 3.58.

\section{Preparation of working electrode.}

The ITO substrate $\left(1 \times 4 \mathrm{~cm}^{2}\right)$ is firstly washed by ethanol, and water under ultrasonic processing for about 30 min then dried in natural environment. Powder of $\mathbf{1}(20 \mathrm{mg})$ was added into $0.5 \mathrm{~mL}$ anhydrous ethanol, then ultrasonicated for $30 \mathrm{~min}$ to form suspension liquid. The working electrodes were prepared by dropping the above suspension $(0.2 \mathrm{~mL})$ onto the surface of the pre-treated ITO by controlling the coating area about $1 \mathrm{~cm}^{2}$, and allowing it to dry at room temperature.

\section{Theoretical calculations of 1 .}

The periodic density functional theory (PDFT) calculations were performed by Material Studio software package ${ }^{3}$ Dmol3 module 4 using the "cif" file of 1 directly. The initial configuration was fully optimized 
by Perdew-Wang (PW91) ${ }^{5}$ generalized gradient approximation (GGA) method with the double numerical basis sets plus polarization function (DNP). The core electrons for metals were treated by effective core potentials (ECP). The self-consistent field (SCF) converged criterion was within $1.0 \times$ $10^{-5}$ hartree atom ${ }^{-1}$ and the converging criterion of the structure optimization was $1.0 \times 10^{-3}$ hartree bohr $^{-1}$. The Brillouin zone is sampled by $1 \times 1 \times 1 \mathrm{k}$-points, and test calculations reveal that the increase of k-points does not affect the results. 


\section{B. Supporting Figures}

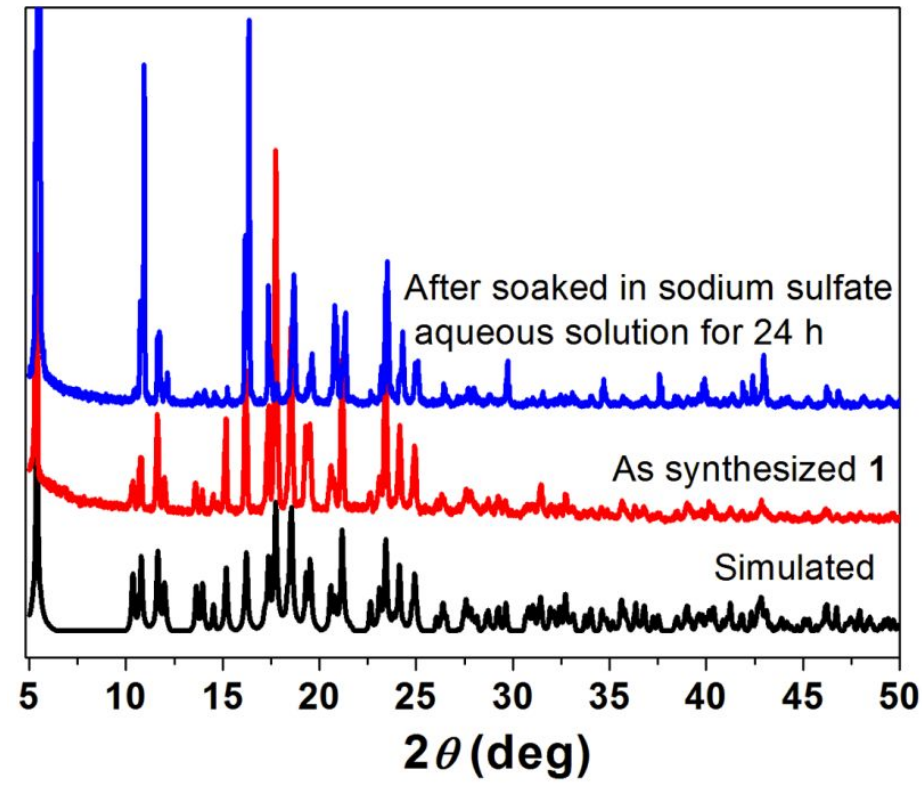

(a)

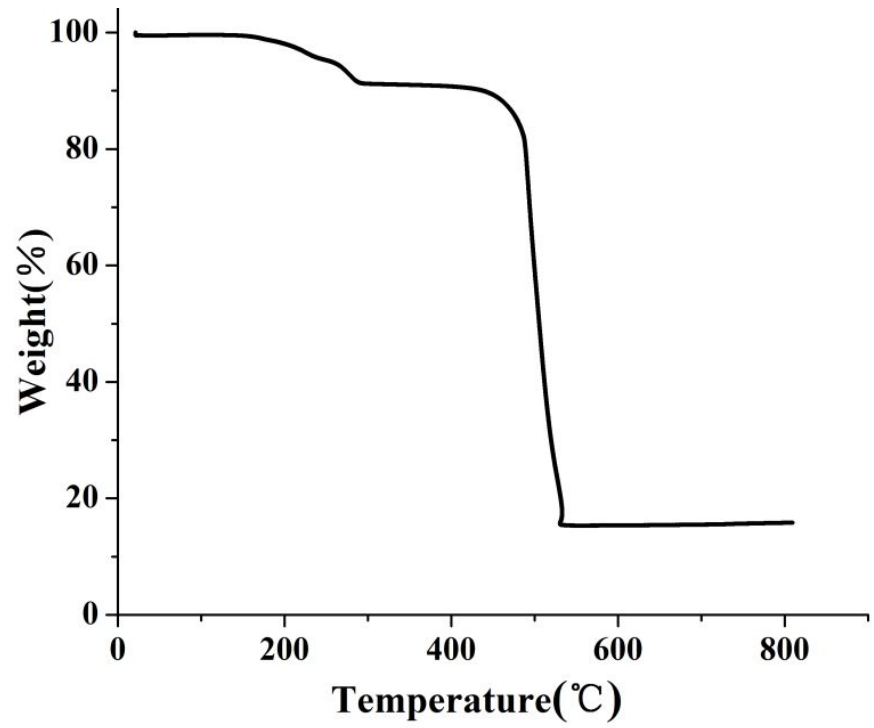

(b)

Fig. S1 (a) PXRD patterns of 1; the simulated, as-synthesized, and after soaked in 0.5 M sodium sulfate aqueous solution for $24 \mathrm{~h}$. (b) Thermogravimetric curve of $\mathbf{1}$. 


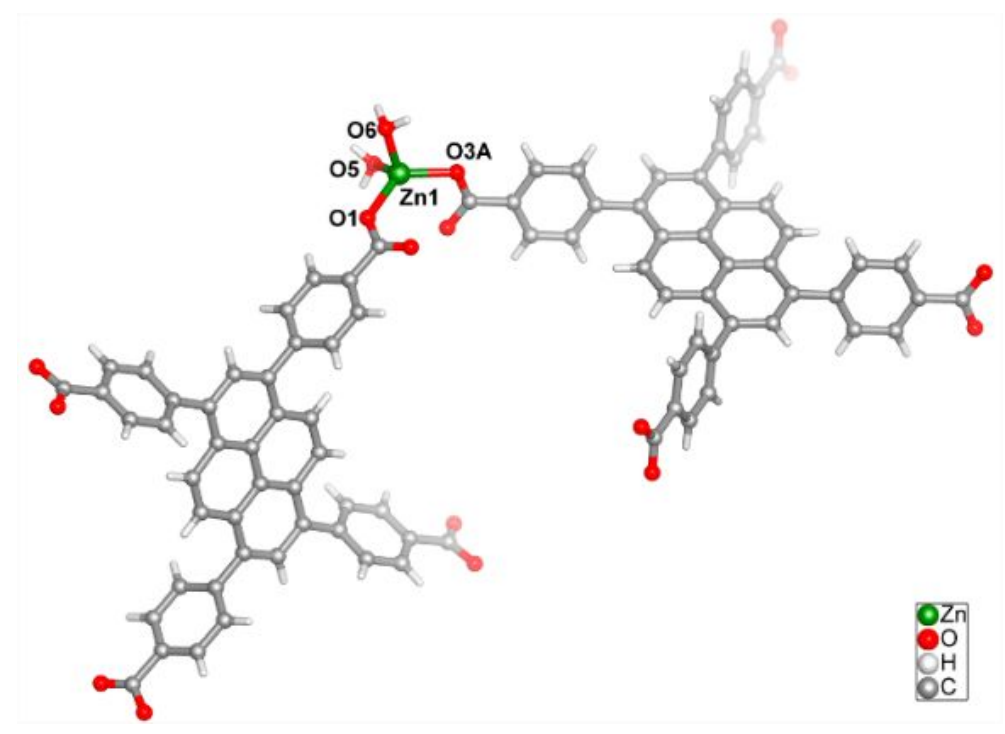

Fig. S2 View of local coordination environment of $\mathrm{Zn}(\mathrm{II})$ ion in 1. Symmetry codes: A -1+X, 1/2-Y, $-1 / 2+Z$.

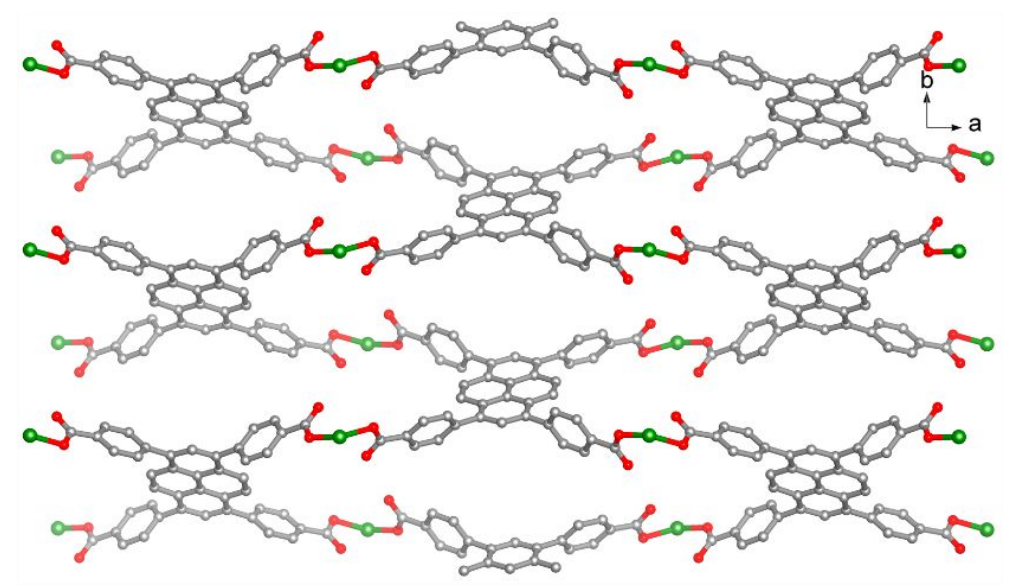

Fig. S3 View of 2D zig-zag layer constructed from TBAPy ligands along the $c$-axis direction. Coordinated water molecules and $\mathrm{H}$ atoms are omitted for clarity. 

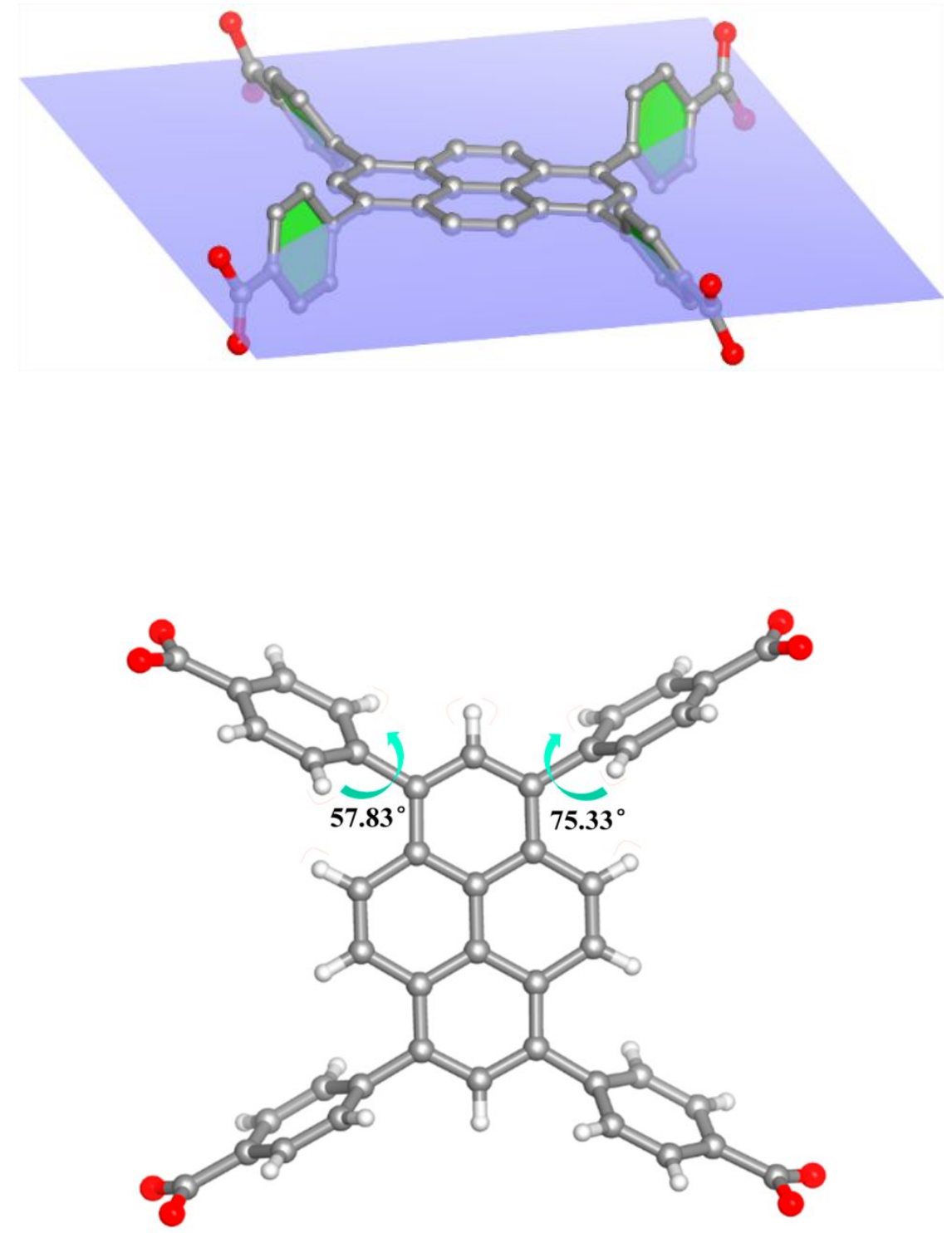

Fig. S4 Rotation of the benzoate group to minimise any steric interactions between the $\mathrm{H}$ atoms of phenyl and pyrene core. 


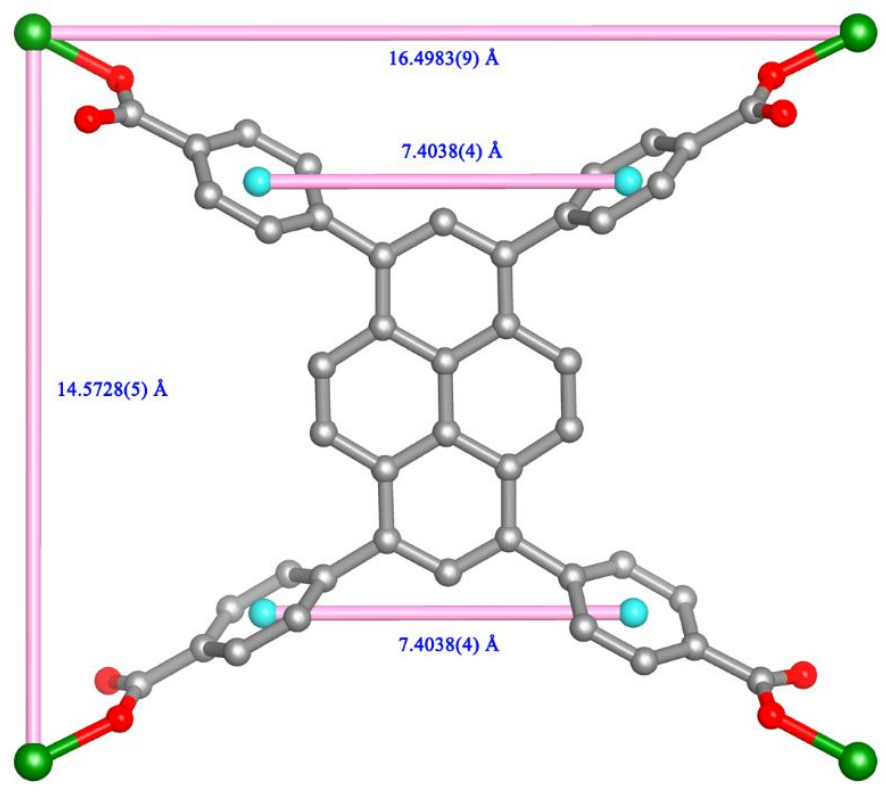

(a)

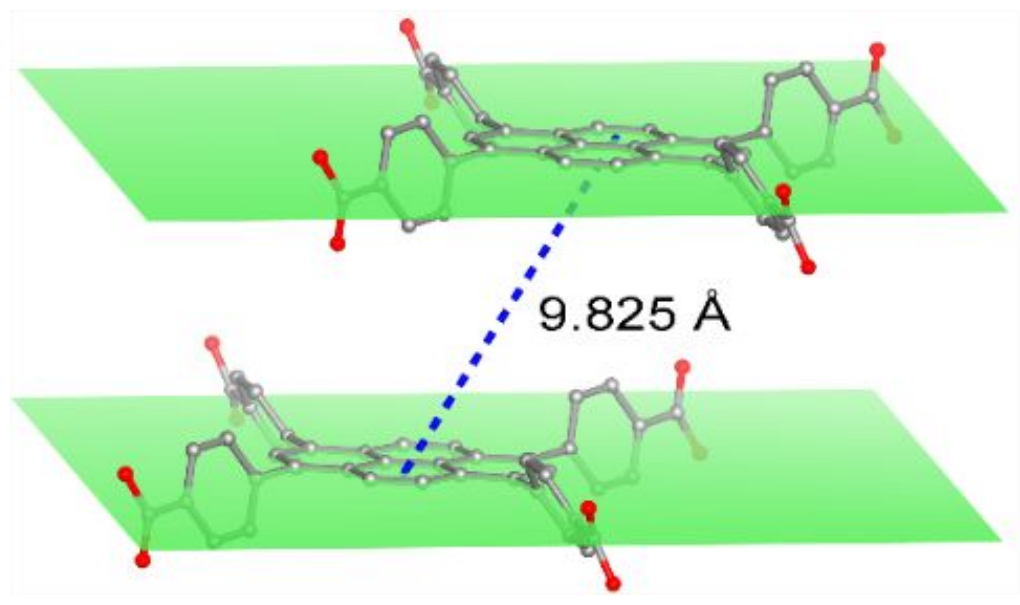

(b)

Fig. S5 (a) The distances between the benzoate centroids of the TBAPy in 1. The separations of $\mathrm{Zn}(\mathrm{II})$ ions linked by one single TBAPy ligand. (b) The separations of two paralleled pyrene cores in one 2D layer. The separations between the benzoate centroids at positions 1 and 3 and at positions 6 and 8 of one single TBAPy ligand in $\mathbf{1}$ are both 7.4038(4) $\AA$. 


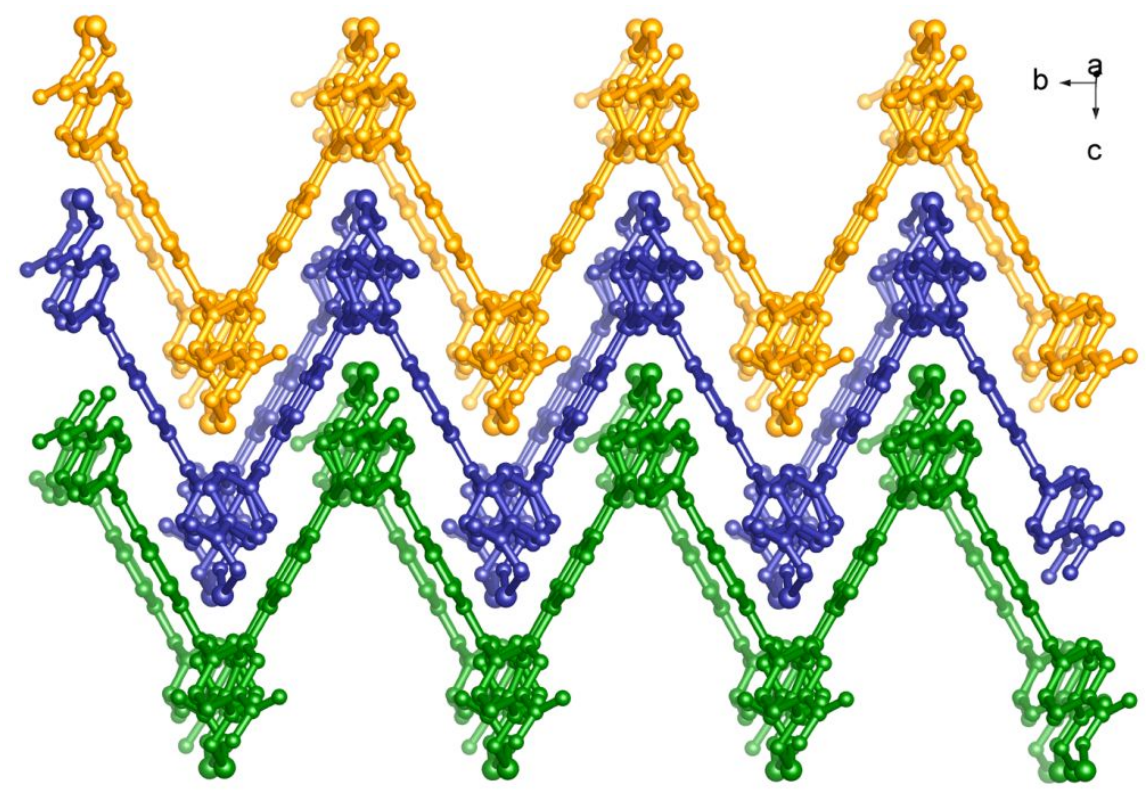

Fig. S6 View of 3D supramolecular framework of 1, which shows a staggered overlap between 2D zig-zag layers. 
The crystal structures of $\mathbf{2}$ and $\mathbf{3}$ show similar planar 2D layers based on Zn(II) paddlewheel units (Fig. S7 and S9); however, the stacking modes of layers are different, and $\mathbf{3}$ has a larger slip stacking of 2D layers compared to 2 . While 4 exhibits a 3D network, in which the TBAPy ligands arrange in a parallel stacking mode with the separation between pyrene cores of $4.798 \AA$ (Fig. S8). The absence of interpenetration or intercalation in 2, 3 and $\mathbf{4}$ can be attributed to the smaller distance of layers. Only in 1, each TBAPy ligand is bonded to four $\mathrm{Zn}$ (II) ions and each $\mathrm{Zn}$ (II) ion is bounded to two TBAPy ligands, resulting in the formation of a 2D zig-zag layer structure (Fig. S6).

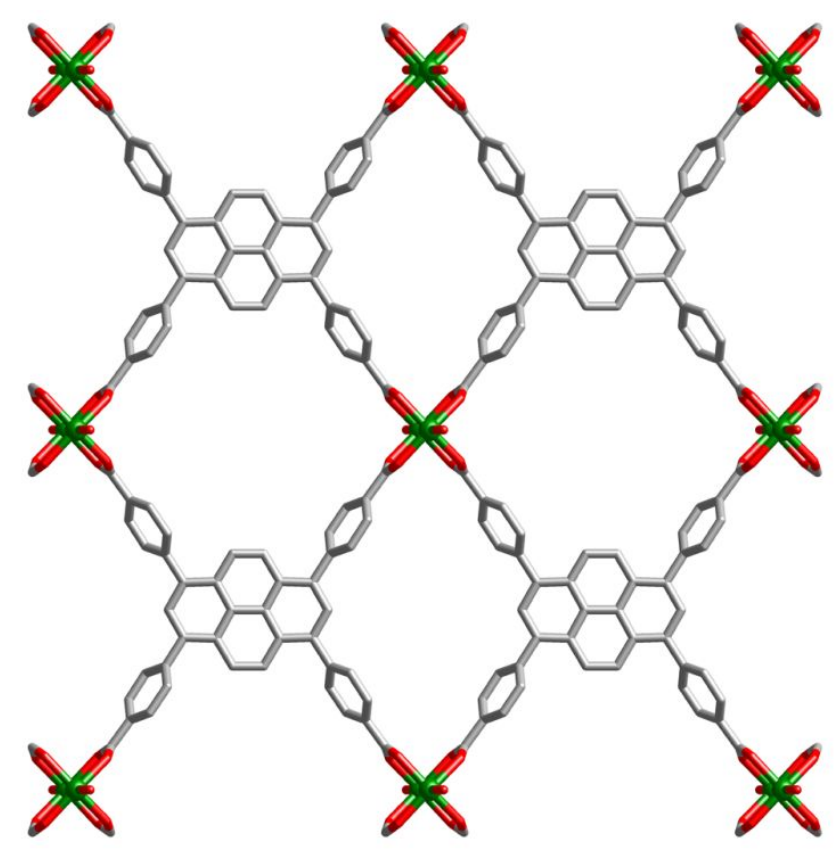

(a)

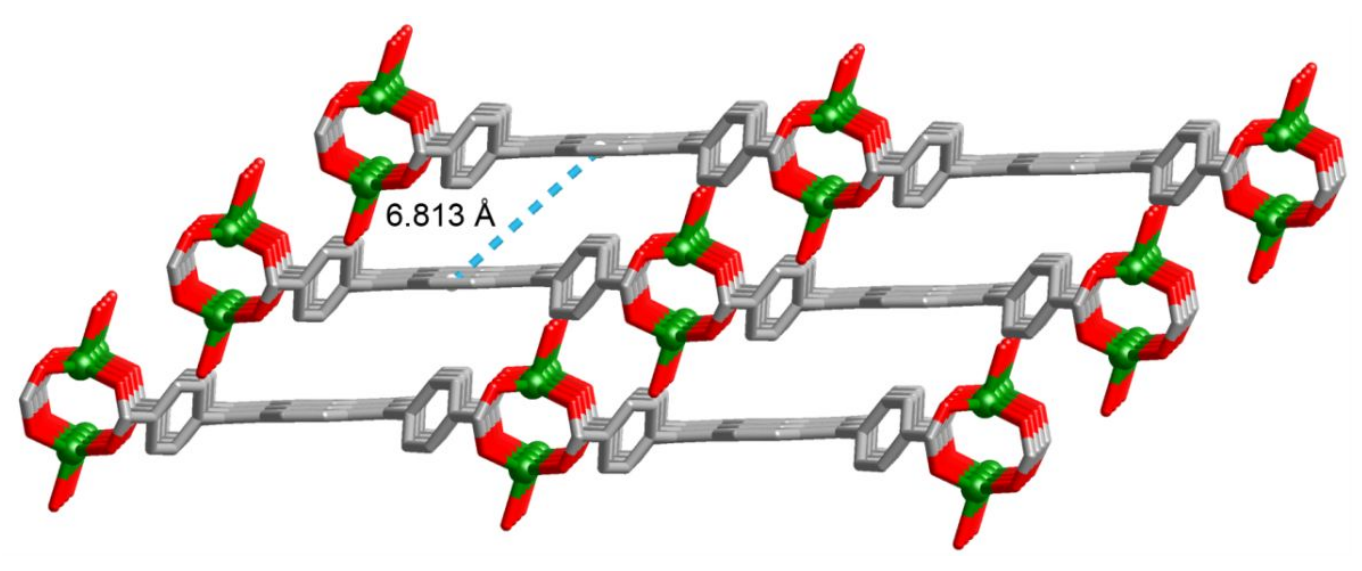

(b)

Fig. S7 View of single (a) and slip stacking (b) 2D layer of $\left[\mathrm{Zn}_{2}(\right.$ TBAPy $\left.)\left(\mathrm{H}_{2} \mathrm{O}\right)_{2}\right] \cdot(\text { Guests })_{\mathrm{x}}(2)$ along [101] and [010] direction, respectively. Reproduced with permission from ref 6. Copyright 2012 American Chemical Society. 


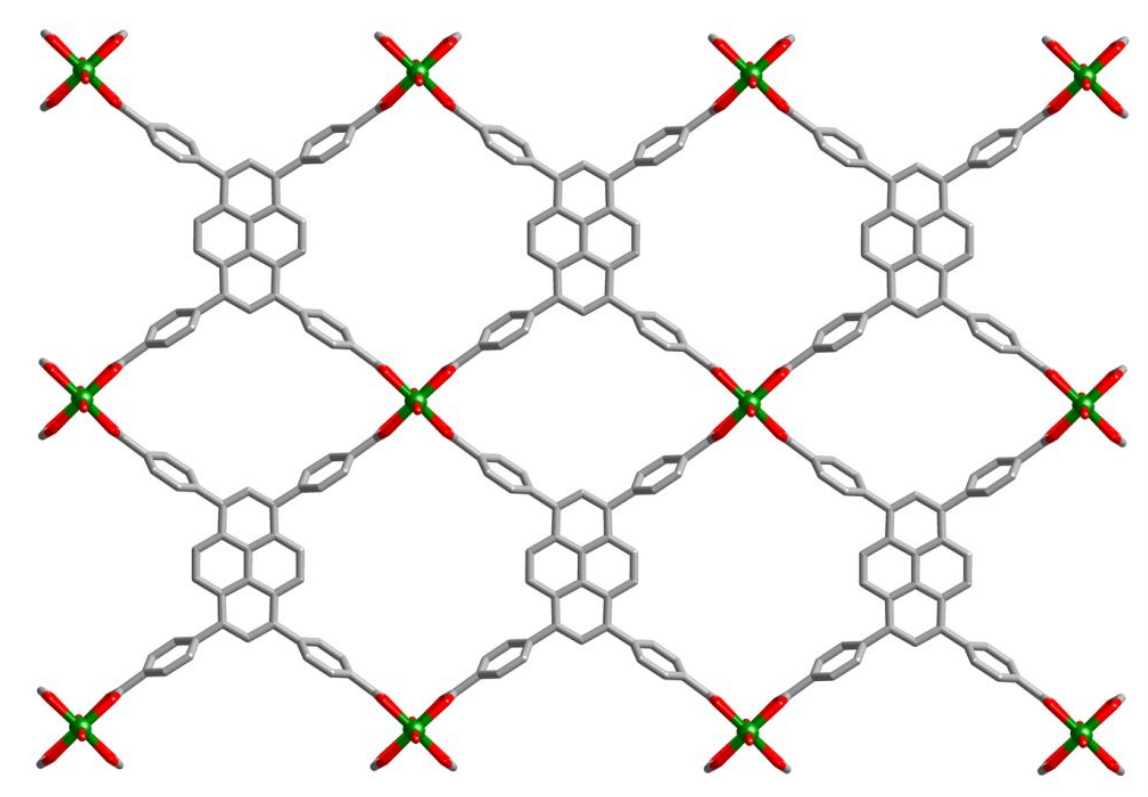

(a)
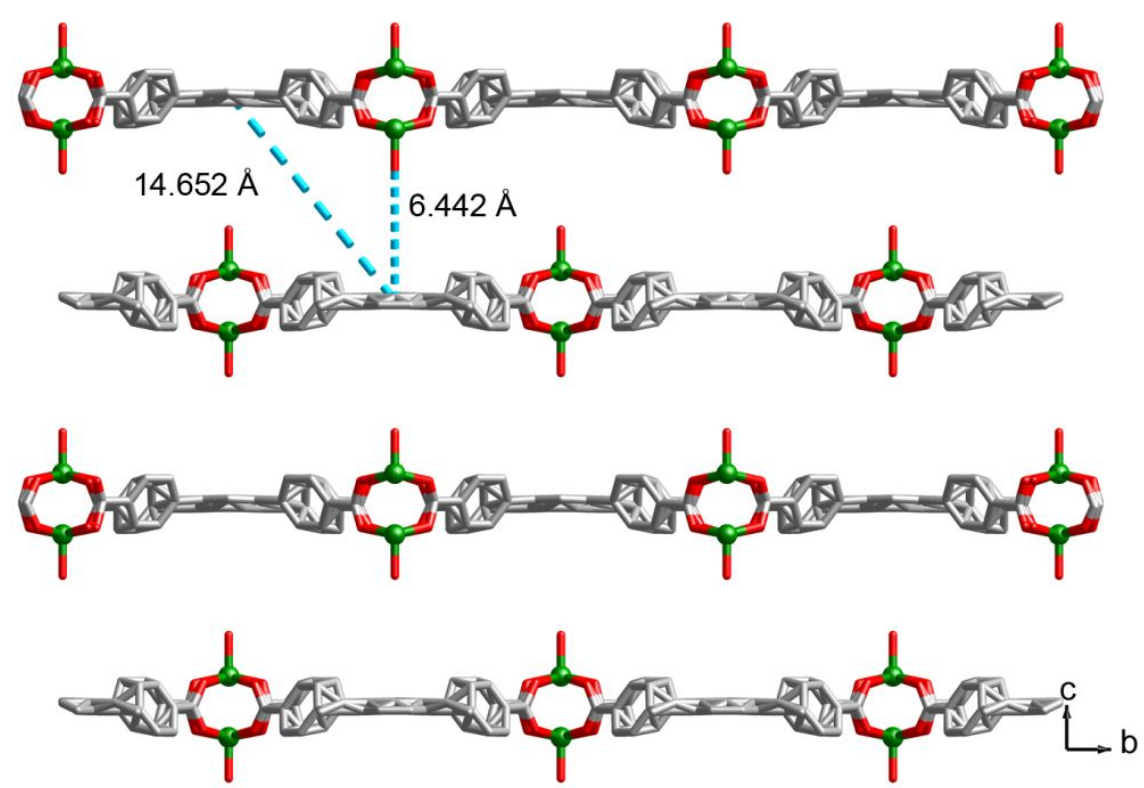

(b)

Fig. S8 View of single (a) and slip stacking (b) 2D layer of $\left[\mathrm{Zn}_{2}(\mathrm{TBAPy})\left(\mathrm{H}_{2} \mathrm{O}\right)_{2}\right] \cdot 3.5 \mathrm{DEF}$ (4). Reproduced with permission from ref 7. Copyright 2015 Royal Society of Chemistry. 


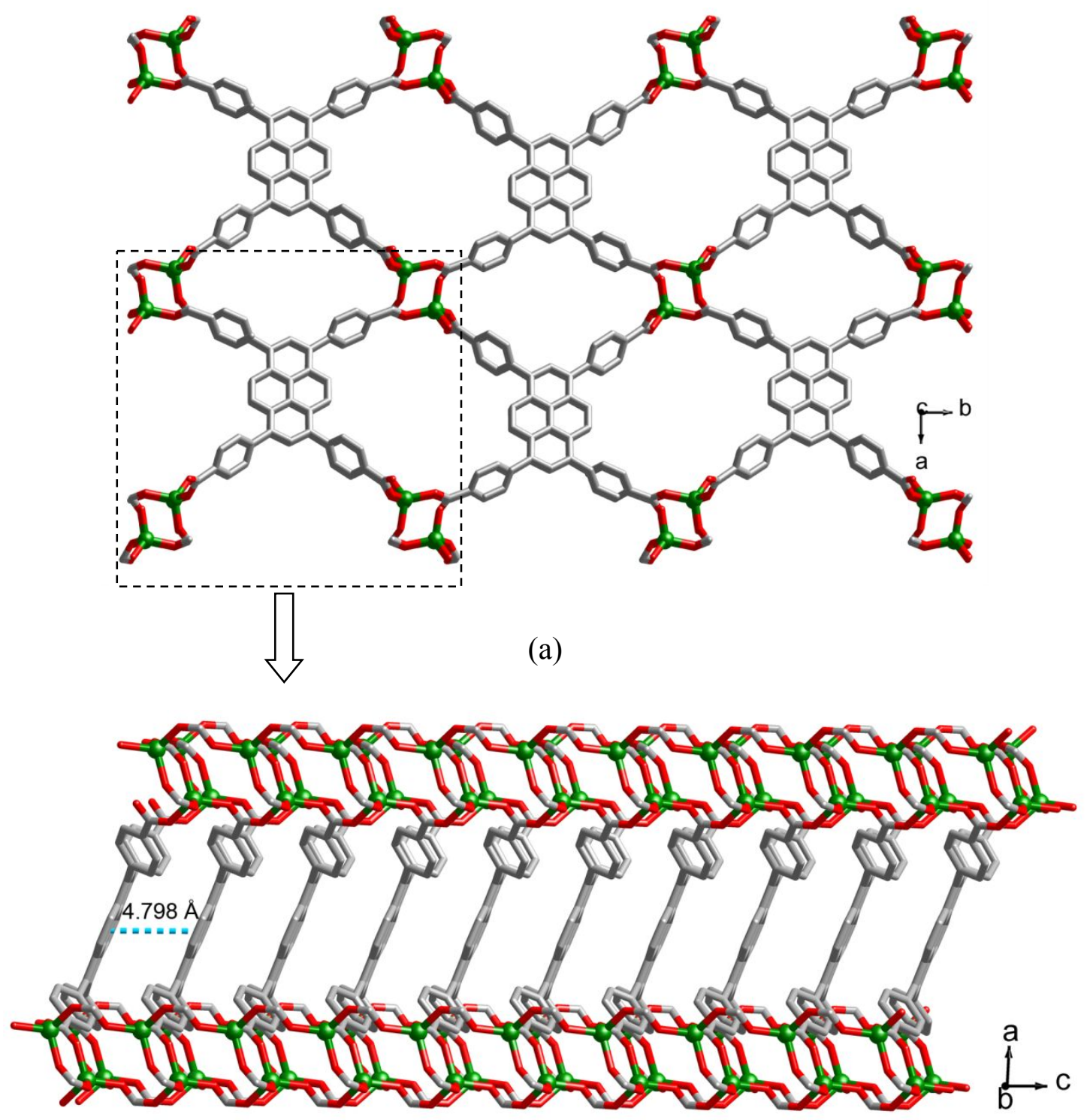

(b)

Fig. S9 View of the 3D network of $\left[\mathrm{Zn}_{2}(\mathrm{TBAPy})\right](3)$ (a), in which TBAPy ligands are arranged in a parallel stacking mode with the separation between pyrene cores of $4.798 \AA$ (b). Reproduced with permission from ref 6. Copyright 2012 American Chemical Society. 


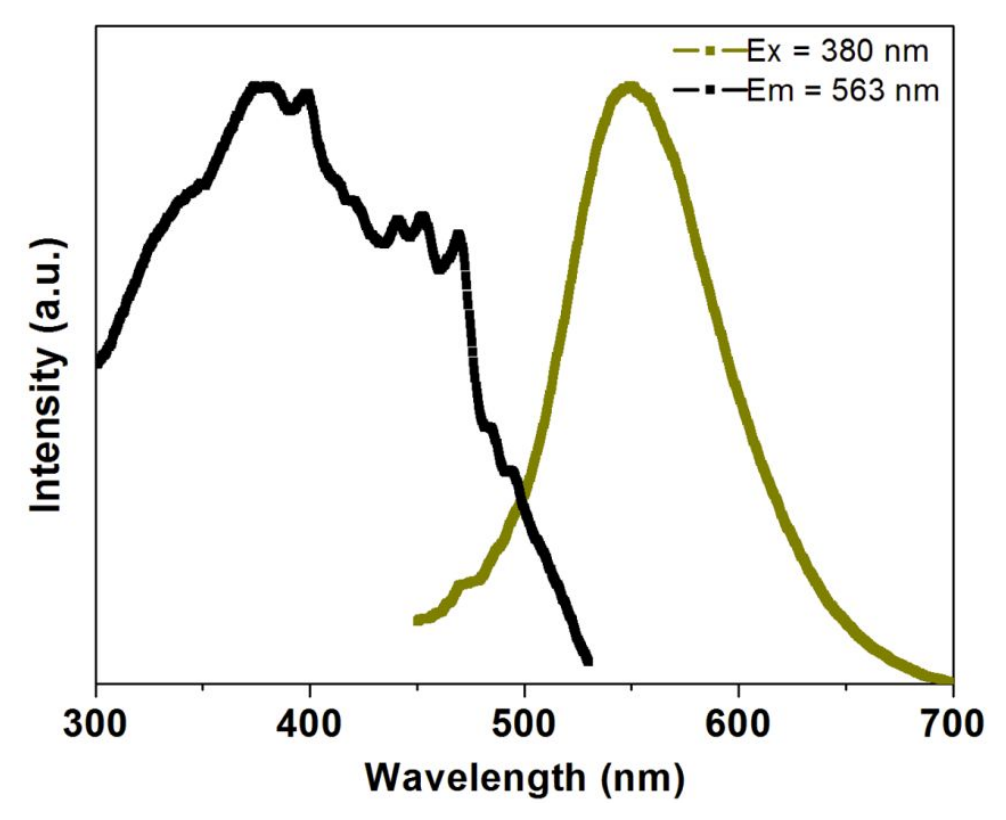

Fig. S10 Normalized excitation and emission spectra of $\mathrm{H}_{4} \mathrm{TBAPy}$ in solid state at room temperature. 


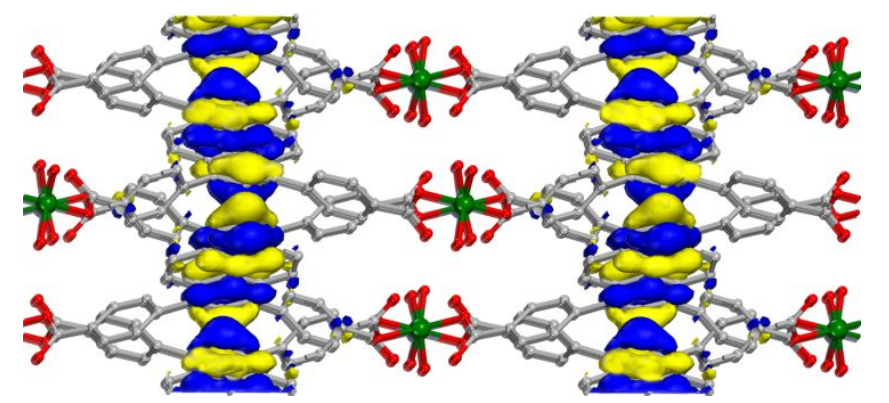

HOMO-3

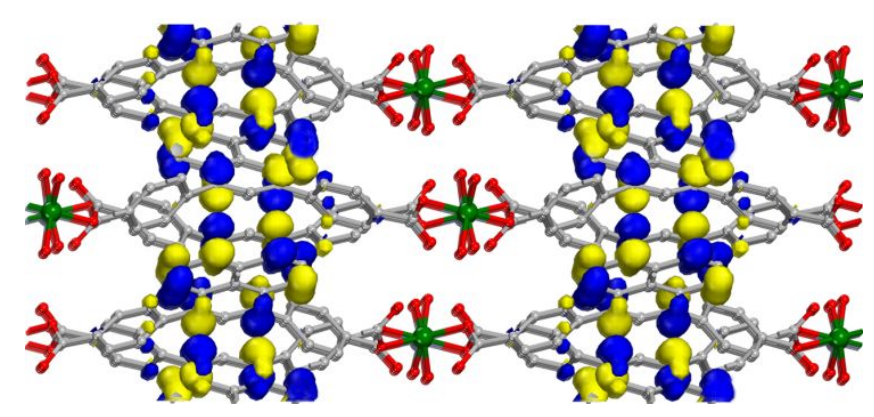

HOMO-1

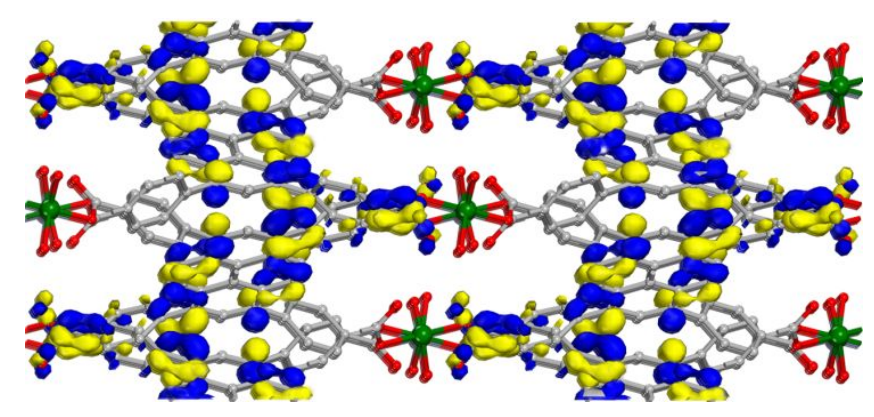

LUMO

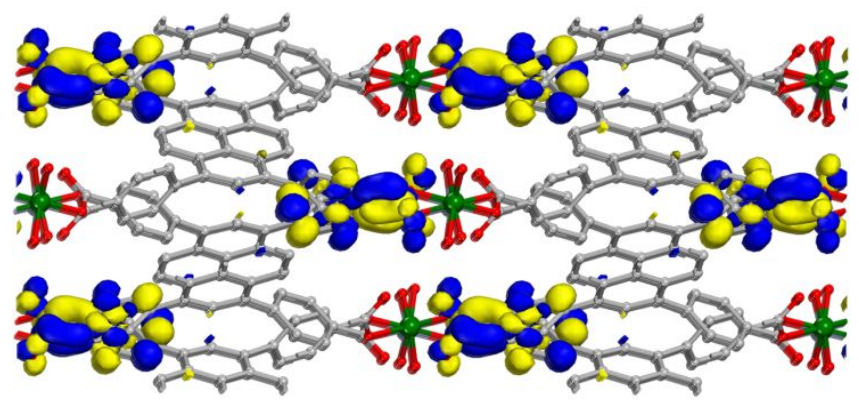

LUMO+2

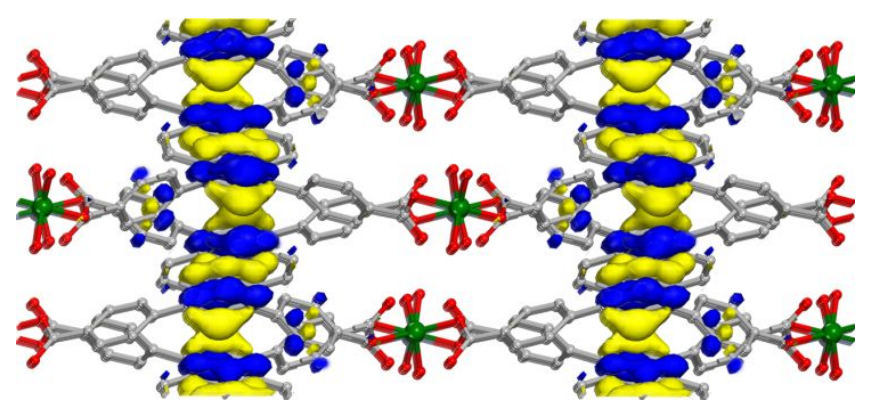

HOMO-2

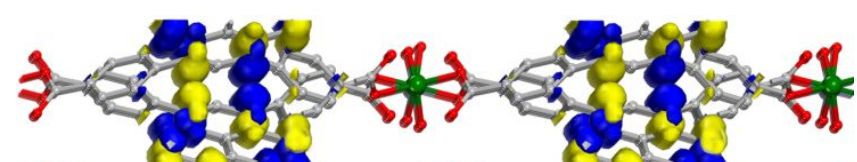

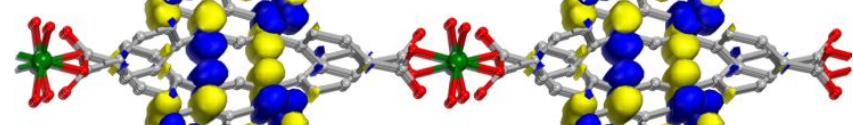

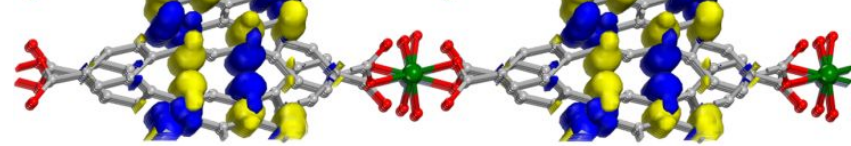

HOMO

LUMO+1

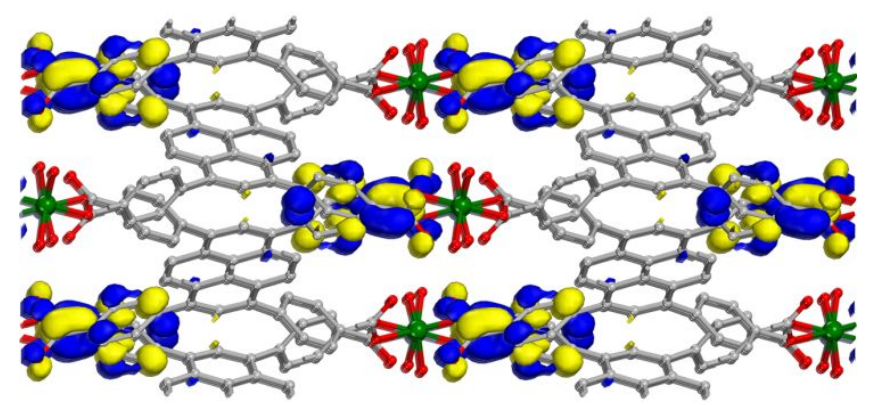

$\mathrm{LUMO}+3$

Fig. S11 The calculated HOMO and LUMO profiles based on PDFT calculations of $\mathbf{1 .}$ 


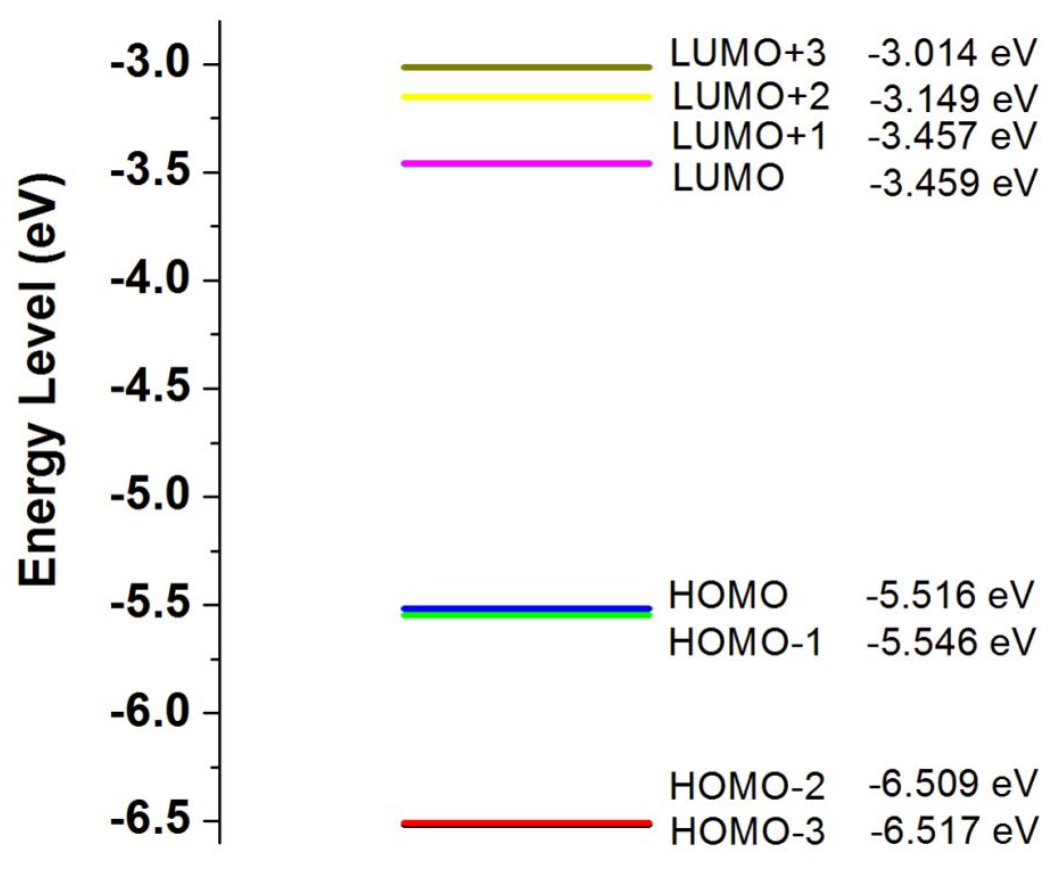

Fig. S12 Calculated orbital energy level of $\mathbf{1}$. 


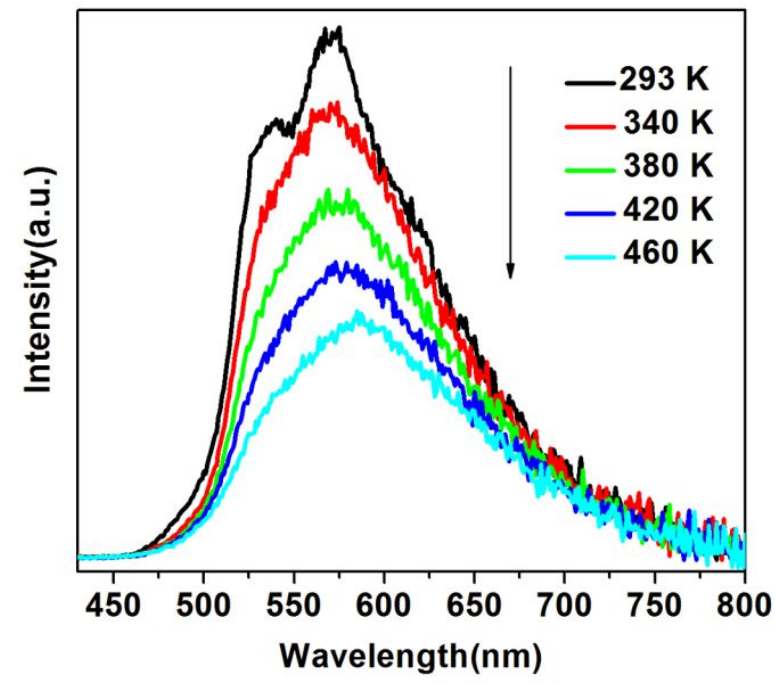

(a)

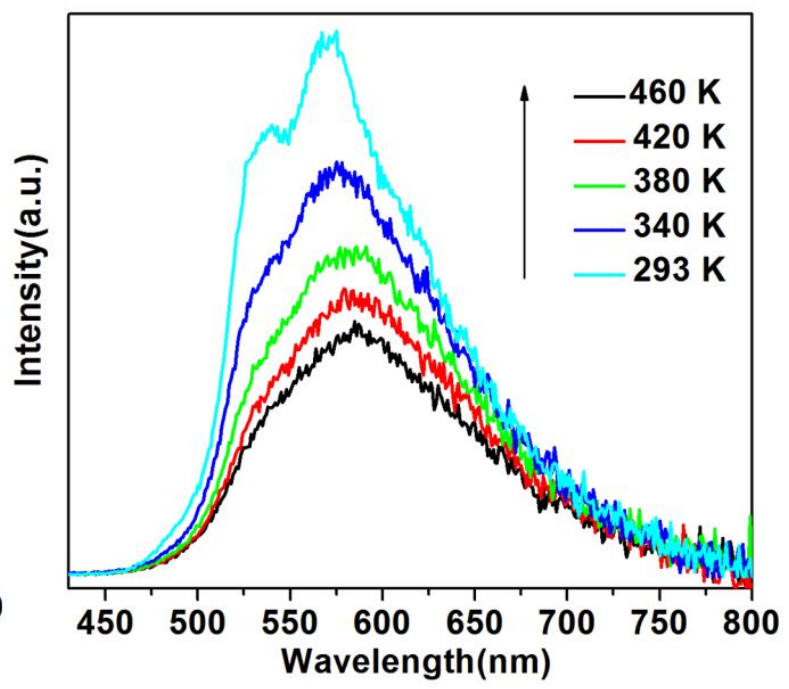

(b)

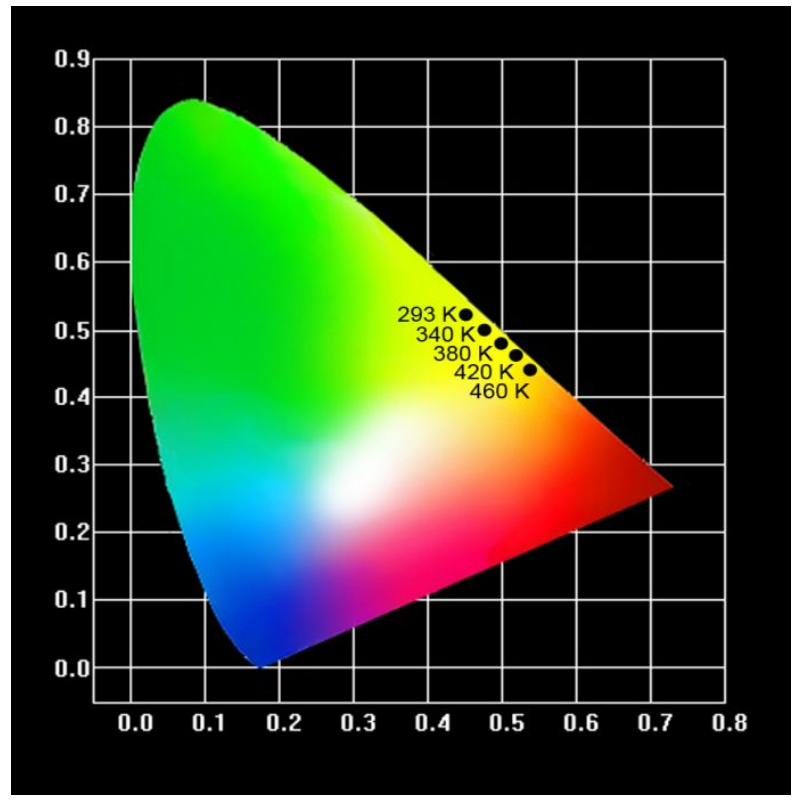

(c)

Fig. S13 Fluorescence spectra of 1 measured from 293 to $460 \mathrm{~K}$ (a) and 460 to $293 \mathrm{~K}$ (b). CIE-1931 chromaticity diagram showing the fluorescence emission of 1 from 293 to $460 \mathrm{~K}$ (c). 


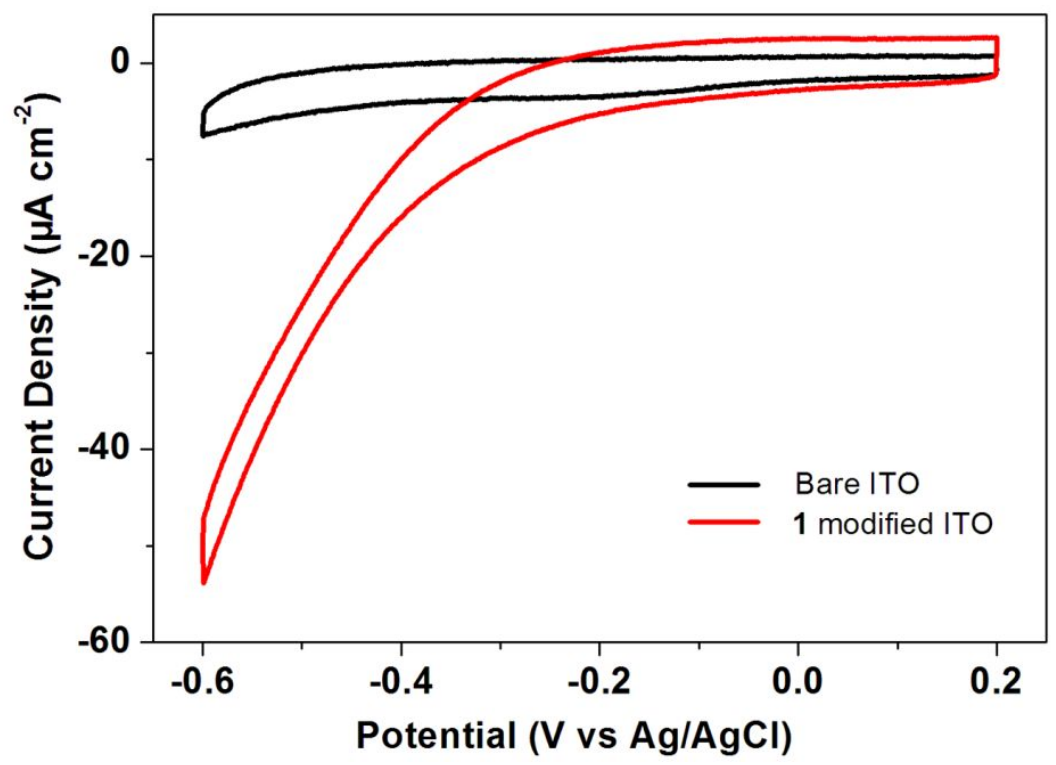

Fig. S14 Cyclic voltammogram of bare ITO and 1 modified ITO in $0.5 \mathrm{M} \mathrm{Na}_{2} \mathrm{SO}_{4}$ aqueous solution.

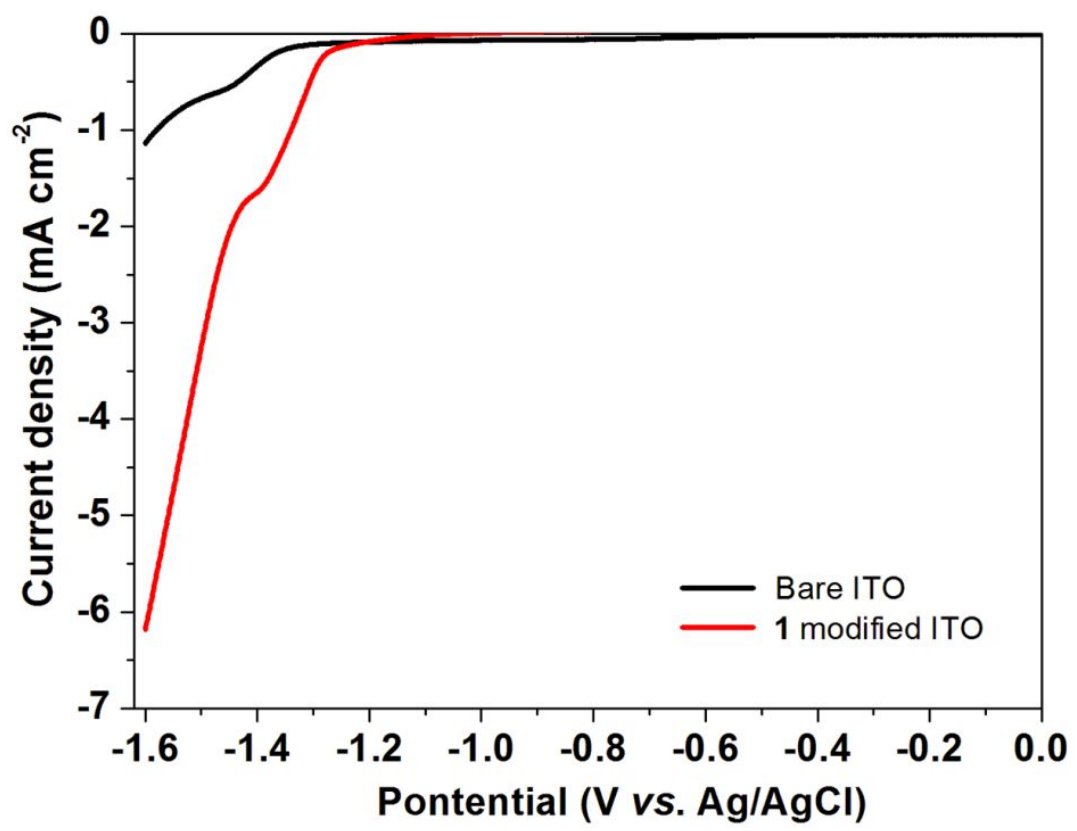

Fig. S15 LSV curves of bare ITO and 1 modified ITO in $0.5 \mathrm{M} \mathrm{Na}_{2} \mathrm{SO}_{4}$ aqueous solution. 


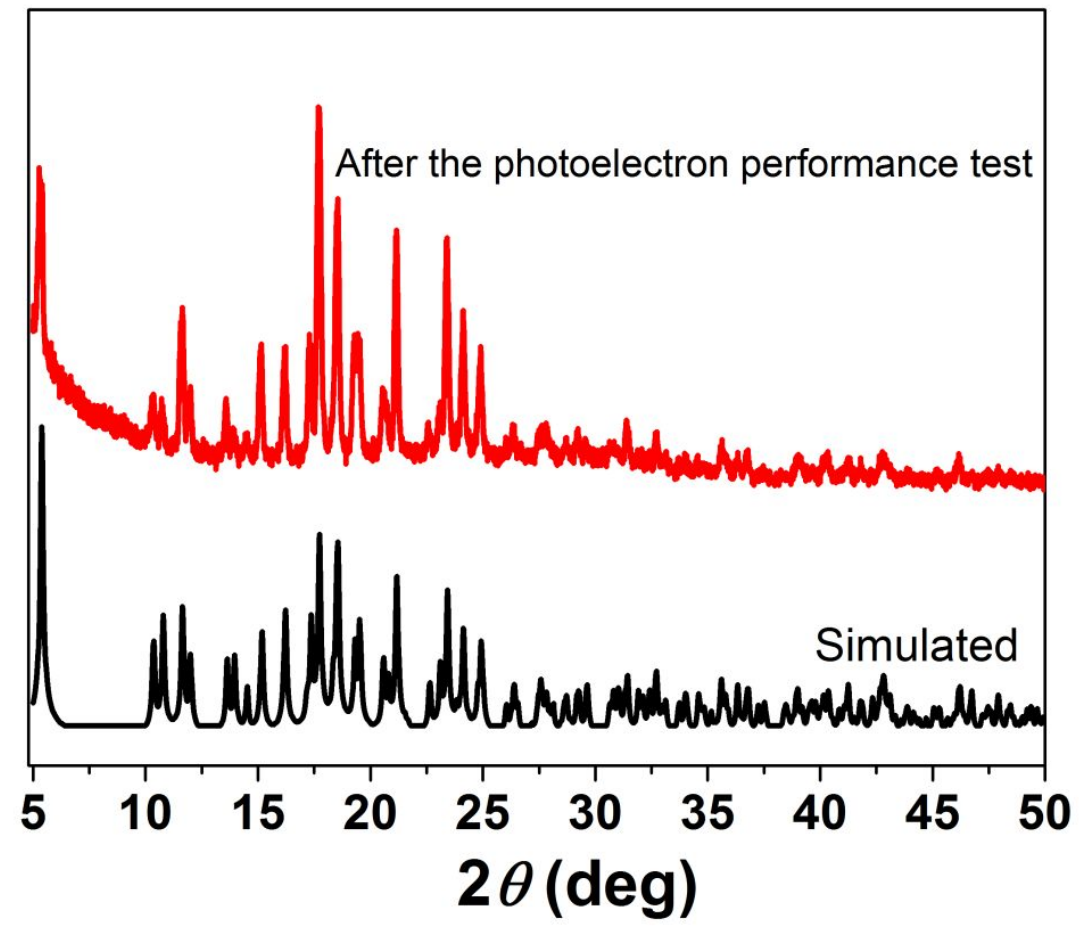

Fig. S16 PXRD patterns of 1; the simulated, and after the photoelectron performance test. 


\section{Supporting Tables}

Table S1. Concentration of TBAPy Linker in TBAPy-based MOFs.

\begin{tabular}{|c|c|c|c|c|c|}
\hline MOF & Volume $/ \AA^{3}$ & $\mathbf{Z}$ & $\begin{array}{l}\text { No. of } \\
\text { TBAPy }\end{array}$ & $\begin{array}{l}{[\text { TBAPy] }} \\
\left(\mathbf{m o l ~ d m}^{-3}\right)\end{array}$ & Ref. \\
\hline$\left[\mathrm{Zn}(\mathrm{TBAPy})_{1 / 2}\left(\mathrm{H}_{2} \mathrm{O}\right)_{2}\right](\mathbf{1})$ & 1937 & 4 & 2 & 1.72 & $\begin{array}{l}\text { this } \\
\text { work }\end{array}$ \\
\hline$\left[\mathrm{Zn}_{2}(\mathrm{TBAPy})\left(\mathrm{H}_{2} \mathrm{O}\right)_{2}\right] \cdot(\text { Guests })_{\mathrm{x}}(\mathbf{2})$ & 1168 & 1 & 1 & 1.42 & 6 \\
\hline$\left[\mathrm{Zn}_{2}(\mathrm{TBAPy})\left(\mathrm{H}_{2} \mathrm{O}\right)_{2}\right] \cdot 3.5 \mathrm{DEF}(\mathbf{3})$ & 4712 & 2 & 2 & 0.71 & 7 \\
\hline$\left[\mathrm{Zn}_{2}\right.$ (TBAPy)] (4) & 2321 & 2 & 2 & 1.43 & 6 \\
\hline $\begin{array}{c}{\left[\mathrm{Ca}_{2}(\mathrm{TBAPy})\left(\mu_{2}-\mathrm{OH}_{2}\right)_{2}\right] \cdot 2 \mathrm{DMF}} \\
(\mathrm{SION}-8)\end{array}$ & 2299 & 4 & 2 & 1.45 & 8 \\
\hline $\begin{array}{c}\left(\mathrm{Me}_{2} \mathrm{NH}_{2}\right)_{3}\left[\mathrm{Eu}_{7}(\right. \\
\left.\left.\mu_{3}-\mathrm{O}\right)_{2}(\mathrm{TBAPy})_{5}\left(\mathrm{H}_{2} \mathrm{O}\right)_{6}\right] \cdot 12.5 \mathrm{DMF} \\
(\mathrm{JXNU}-5)\end{array}$ & 5874 & 1 & 5 & 1.41 & 9 \\
\hline $\begin{array}{c}{\left[\mathrm{Mg}_{3}\left(\mathrm{H}_{3} \mathrm{O}\right)_{2}(\mathrm{TBAPy})_{2}\left(\mu_{2}-\mathrm{OH}_{2}\right)_{2}\left(\mathrm{H}_{2} \mathrm{O}\right)_{2}\right] \cdot 6} \\
5(\mathrm{DMF}) \cdot\left(\mathrm{H}_{2} \mathrm{O}\right) \cdot 0.5(\text { dioxane }) \\
(\mathrm{MIT}-26)\end{array}$ & 2459 & 4 & 2 & 1.35 & 10 \\
\hline $\begin{array}{l}{\left[\mathrm{Mg}_{1.5}(\mathrm{HTBAPy})\left(\mathrm{H}_{2} \mathrm{O}\right)_{2}\right] \cdot 3 \mathrm{DMF}} \\
\text { (SION-7) }\end{array}$ & 2450 & 1 & 2 & 1.35 & 11 \\
\hline $\begin{array}{c}{\left[\mathrm{Mn}_{2}(\mathrm{TBAPy})\left(\mathrm{H}_{2} \mathrm{O}\right)_{2}\right] \cdot \mathrm{DMF} \cdot \mathrm{H}_{2} \mathrm{O}} \\
(\mathrm{ROD}-6)\end{array}$ & 5034 & 4 & 4 & 1.32 & 12 \\
\hline $\begin{array}{c}{\left[\mathrm{Cd}_{2}(\mathrm{TBAPy})\left(\mathrm{H}_{2} \mathrm{O}\right)_{2}\right] \cdot \mathrm{DMF} \cdot 0.5 \text { dioxane }} \\
(\mathrm{ROD}-8)\end{array}$ & 5085 & 4 & 4 & 1.31 & 13 \\
\hline$\left[\mathrm{Ni}_{3}\left(\mu_{3}-\mathrm{OH}\right)_{2}(\mathrm{TBAPy})\left(\mathrm{H}_{2} \mathrm{O}\right)_{4}\right] \cdot$ Guests & 5475 & 4 & 4 & 1.21 & 14 \\
\hline $\begin{array}{c}\left(\left[\operatorname{In}_{2}(\mathrm{OH})_{2} \mathrm{TBAPy}\right]\right. \\
(\mathrm{ROD}-7)\end{array}$ & 3488 & 2 & 2 & 0.95 & 15 \\
\hline NU-901 & 1 & 1 & 1 & 0.65 & 16 \\
\hline $\begin{array}{c}\mathrm{Zr}_{6}\left(\mu_{3}-\mathrm{OH}\right)_{8}(\mathrm{OH})_{8}(\mathrm{TBAPy})_{2} \\
(\mathrm{NU}-1000)\end{array}$ & 22145 & 3 & 6 & 0.41 & 17 \\
\hline $\begin{array}{c}{\left[\left(\mathrm{CH}_{3}\right)_{2} \mathrm{NH}_{2}\right]_{4}\left[\left(\mathrm{UO}_{2}\right)_{4}(\mathrm{TBAPy})_{3}\right]} \\
(\mathrm{NU}-1300)\end{array}$ & 166897 & 16 & 24 & 0.24 & 18 \\
\hline
\end{tabular}


Table S2. Crystallographic data and experimental details for $\mathbf{1 .}$

\begin{tabular}{|c|c|}
\hline Complex & 1 \\
\hline Empirical formula & $\mathrm{C}_{22} \mathrm{H}_{15} \mathrm{O}_{6} \mathrm{Zn}$ \\
\hline Formula weight & 440.71 \\
\hline Temperature/K & 293(2) \\
\hline Crystal system & monoclinic \\
\hline Space group & $P 2_{1} / c$ \\
\hline$a / \AA$ & $16.9422(8)$ \\
\hline$b / \AA$ & $9.8247(4)$ \\
\hline$c / \AA$ & $12.0215(5)$ \\
\hline$\alpha /^{\circ}$ & 90 \\
\hline$\beta /^{\circ}$ & $104.495(5)$ \\
\hline$\gamma /{ }^{\circ}$ & 90 \\
\hline Volume $/ \AA^{3}$ & 1937.31(15) \\
\hline$Z$ & 4 \\
\hline$\rho_{\text {calc }} \mathrm{g} / \mathrm{cm}^{3}$ & 1.511 \\
\hline$\mu / \mathrm{mm}^{-1}$ & 1.304 \\
\hline $\mathrm{F}(000)$ & 900.0 \\
\hline Crystal size $/ \mathrm{mm}^{3}$ & $0.28 \times 0.25 \times 0.22$ \\
\hline Radiation & $\operatorname{MoK} \alpha(\lambda=0.71073)$ \\
\hline $2 \Theta$ range for data collection $/{ }^{\circ}$ & 6.74 to 50.994 \\
\hline Index ranges & $-15 \leq \mathrm{h} \leq 20,-11 \leq \mathrm{k} \leq 10,-14 \leq 1 \leq 14$ \\
\hline Reflections collected & 14671 \\
\hline Independent reflections & $3602\left[R_{\text {int }}=0.0445, R_{\text {sigma }}=0.0373\right]$ \\
\hline Data/restraints/parameters & $3602 / 0 / 262$ \\
\hline Goodness-of-fit on $\mathrm{F}^{2}$ & 1.145 \\
\hline Final ${ }^{a}$ Rindexes $[\mathrm{I}>=2 \sigma(\mathrm{I})]$ & $R_{1}=0.0744, w R_{2}=0.1772$ \\
\hline Final a $R$ indexes [all data] & $R_{1}=0.0789, w R_{2}=0.1789$ \\
\hline Largest diff. peak/hole / e $\AA^{-3}$ & $2.88 /-1.08$ \\
\hline
\end{tabular}


Table S3. Selected bond distances / $\mathrm{A}$ and bond angles $/{ }^{\circ}$ for 1 .

\begin{tabular}{llll}
\hline Zn1-O1 & $1.939(4)$ & Zn1-O5 & $2.012(5)$ \\
Zn1-O3 $^{1}$ & $1.961(4)$ & Zn1-O6 & $2.022(5)$ \\
O1-Zn1-O3 $^{1}$ & $126.28(18)$ & O3 ${ }^{1}-Z n 1-O 5$ & $109.3(2)$ \\
O1-Zn1-O5 & $100.8(2)$ & O3 $^{1}-Z n 1-O 6$ & $105.11(19)$ \\
O1-Zn1 O6 & $104.9(2)$ & O5-Zn1-O6 & $109.9(2)$ \\
\hline
\end{tabular}

Symmetry operations: ${ }^{1}-1+\mathrm{X}, 1 / 2-\mathrm{Y},-1 / 2+Z$; 


\section{Supporting References}

[1] CrysAlisPro, Rigaku Oxford Diffraction, Version 1.171.39.6a.

[2] G. M. Sheldrick, Acta Crystallogr. Sect. A, 2008, 64, 112.

[3] (a) B. Delley, J. Chem. Phys., 1990, 92, 508; (b) B. Delley, J. Chem. Phys., 2000, 113, 7756.

[4] Dmol ${ }^{3}$ Module, MS Modeling, Version 2.2; Accelrys Inc.: San, Diego, 2003.

[5] J. P. Perdew, J. A. Chevary, S. H. Vosko, K. A. Jackson, M. R. Pederson, D. J. Singh, C. Fiolhais, Phys. Rev. B, 1992, 46, 6671.

[6] K. C. Stylianou, J. Rabone, S. Y. Chong, R. Heck, J. Armstrong, P. V. Wiper, K. E. Jelfs, S. Zlatogorsky, J. Bacsa, A. G. McLennan, C. P. Ireland, Y. Z. Khimyak, K. M. Thomas, D. Bradshaw and M. J. Rosseinsky, J. Am. Chem. Soc., 2012, 134, 20466.

[7] A. V. Vinogradov, H. Zaake-Hertling, A. S. Drozdov, P. Loennecke, G. A. Seisenbaeva, V. G. Kessler, V. V. Vinogradov and E. Hey-Hawkins, Chem. Commun., 2015, 51, 17764.

[8] A. Gładysiak, K. S. Deeg, I. Dovgaliuk, A. Chidambaram, K. Ordiz, P. G. Boyd, S. M. Moosavi, D. Ongari, J. A. R. Navarro, B. Smit and K. C. Stylianou, ACS Appl. Mater. Interfaces, 2018, 10, 36144.

[9] R. Liu, Q.-Y. Liu, R. Krishna, W. Wang, C.-T. He and Y.-L. Wang, Inorg. Chem., 2019, 58, 5089.

[10] S. S. Park, C. H. Hendon, A. J. Fielding, A. Walsh, M. O'Keeffe and M. Dinca, J. Am. Chem. Soc., 2017, 139, 3619.

[11] A. Gladysiak, T. N. Nguyen, R. Bounds, A. Zacharia, G. Itskos, J. Reimer and K. Stylianou, Chem. Sci., 2019, 10.1039/C9SC01422E.

[12] R.-J. Li, M. Li, X.-P. Zhou, D. Li and M. O'Keeffe, Chem. Commun., 2014, 50, 4047.

[13] R.-J. Li, M. Li, X.-P. Zhou, S. W. Ng, M. O'Keeffe and D. Li, CrystEngComm, 2014, 16, 6291.

[14] K. C. Stylianou, J. Bacsa, D. Bradshaw and M. J. Rosseinsky, Z. Anorg. Allg. Chem., 2014, 640, 2123.

[15] K. C. Stylianou, R. Heck, S. Y. Chong, J. Bacsa, J. T. A. Jones, Y. Z. Khimyak, D. Bradshaw and M. J. Rosseinsky, J. Am. Chem. Soc., 2010, 132, 4119.

[16] C.-W. Kung, T. C. Wang, J. E. Mondloch, D. Fairen-Jimenez, D. M. Gardner, W. Bury, J. M. Klingsporn, J. C. Barnes, R. Van Duyne, J. F. Stoddart, M. R. Wasielewski, O. K. Farha and J. T. Hupp, Chem. Mater., 2013, 25, 5012.

[17] J. E. Mondloch, W. Bury, D. Fairen-Jimenez, S. Kwon, E. J. DeMarco, M. H. Weston, A. A. Sarjeant, S. T. Nguyen, P. C. Stair, R. Q. Snurr, O. K. Farha and J. T. Hupp, J. Am. Chem. Soc., 2013, 135, 10294.

[18] P. Li, N. A. Vermeulen, X. Gong, C. D. Malliakas, J. F. Stoddart, J. T. Hupp and O. K. Farha, Angew. Chem. Int. Ed., 2016, 55, 10358. 